\title{
Is the axial length a risk factor for post-LASIK myopic regression?
}

\author{
Amr A. Gab-Alla ${ }^{1}$ (D) \\ Received: 13 July 2020 / Revised: 9 October 2020 / Accepted: 22 October 2020 / Published online: 31 October 2020 \\ (C) The Author(s) 2020
}

\begin{abstract}
Purpose To assess the relationship between the axial length and post-LASIK regression in myopic patients.

Methods This is a retrospective case series study conducted at a private eye centre, Ismailia, Egypt. The clinical records of the patients, who experienced LASIK to correct myopia from January 2016 to January 2018, were analysed for myopic regression. The patients were operated on, examined, and followed-up 1 year by one surgeon (AAG).

Results This study included 1219 patients (2316 eyes) with myopia. Mean \pm SD of pre-operative spherical equivalent (SE) was $4.3 \pm 2.1 \mathrm{D}$, range $(-0.50$ to $-10.0 \mathrm{D})$. Mean $\pm \mathrm{SD}$ age of the patients was $26.4 \pm 6.8$ years, range ( 21 to 50 years). Male to female ratio was 30.5 to $69.5 \%$. The cumulative incidence rate of myopic regression according to the medical records of the patients was $25.12 \%$ (582 eyes out of total 2316 eyes) along the 2 years of this study (12.6\% per year). Of the total patients, $14.94 \%$ had preoperative high myopia, $35.84 \%$ had pre-operative moderate myopia, and $49.2 \%$ had pre-operative low myopia. Of the patients with myopic regression, $52.6 \%$ had pre-operative high myopia, 34\% had pre-operative moderate myopia, and $13.4 \%$ had preoperative low myopia. The mean \pm SD of the axial length of the patients with myopic regression was $26.6 \pm 0.44 \mathrm{~mm}$, range $(26.0$ to $27.86 \mathrm{~mm})$, while the mean $\pm \mathrm{SD}$ of the axial length of other patients with stable refraction was $24.38 \pm 0.73 \mathrm{~mm}$, range $(22.9$ to $25.9 \mathrm{~mm})(t$ test statistic $=69.3 ; P$ value $<0.001)$.
\end{abstract}

Conclusions Pre-operative high axial length increases the risk of myopic regression after LASIK.

\section{Key messages}

What was known?

- The exact mechanism of Post-LASIK myopic regression is unclear. High pre-operative sphere, high astigmatism, corneal steepness, and older age have been well recognized to be associated with myopic regression.

What This Paper Adds:

- Axial length $>26 \mathrm{~mm}$ is a risk factor for post-LASIK myopic regression.

- Axial length should be evaluated pre-LASIK and before LASIK enhancement.

Keywords Axial length · LASIK · Myopia $\cdot$ Correlation · Regression

Amr A. Gab-Alla

amrophth@hotmail.com

1 Faculty of Medicine, Ophthalmology Department, Suez Canal University, Ring Road, Ismailia, Egypt

\section{Introduction}

Post-laser in situ keratomileusis myopic regression can be defined as gradual, incomplete, or complete loss of primary correction that limits the efficiency, predictability, and longterm stability of laser in situ keratomileusis (LASIK) [1].

Although LASIK techniques and surgeon experience have improved over the past 20 years resulting in better outcomes, 
myopic regression after LASIK is inevitable, and the exact mechanism of it is unclear and under-explored [2]. Previous studies had recorded some regression-related factors before and after LASIK and suggested a forward shift of the cornea as an explanation of myopic regression [3-5]. Patel et al. [6] recorded a myopic regression rate of $16 \%$ along the 3-month follow-up period of their study. Hersh et al. [7] recorded a $10.5 \%$ incidence of myopic regression in their study (3-year follow-up period). They stated that high primary corrections, astigmatism, and old age were significant risk factors for it. Liu et al. [8] recorded a rate of $21 \%$ myopic regression along 5 years of their study. Randleman et al. [9] recorded a $6.3 \%$ enhancement rate along 1-year follow-up period and stated that patients with high myopic errors were more expected to have enhancement. In long-term studies, Alio et al. [10] recorded retreatment rates ranging from 20 to $27 \%$ in their study with 10 years follow-up.

Another factor that might influence the post-LASIK myopic regression is the axial length of the eye. So, this study aimed to assess the relationship between refractive regression and the axial length in myopic patients.

\section{Patients and methods}

This is a retrospective and case series study that included patients who experienced LASIK to correct myopia from January 2016 to January 2018, at a private eye centre, Ismailia, Egypt.

Inclusion criteria were age over 21 years, intraocular pressure (IOP) less than $21 \mathrm{mmHg}$, central corneal thickness $(\mathrm{CCT})>500 \mu \mathrm{m}$ at the thinnest point and the calculated residual stromal bed after treatment $>60 \%$ of the total corneal thickness, a regular corneal topography pattern (Sirius, CSO, Florence, Italy), and no history of diabetes mellitus, autoimmune diseases, or earlier ocular surgeries. Patients with insufficient follow-up were excluded from the study.

Pre-operatively, patients experienced standard eye examinations, including slit-lamp examination, indirect fundoscopy, and refraction (cycloplegic and manifest and presented as spherical equivalent -0.5 to $-10.00 \mathrm{D}$ ), intraocular pressure (IOP) by applanation tonometry and ocular response analyser (ORA), and axial length (Lenstar, HAAG-STREIT, USA).

Laser in situ keratomileusis was performed using $500 \mathrm{kHz}$ Amaris excimer laser (Schwind eye-tech-solutions, Kleinostheim, Germany). Corneal flaps with superior hinge were cut with Moria M2 microkeratome (Moria, Antony, France). The optical zones ranged from 5.8 to $7.0 \mathrm{~mm}$ in diameter. The patients had routine procedures. All surgeries targeted distance vision.
Post-operatively, the patients with stable refraction were examined at the 1st day; 1 st week; 1st, 3rd, and 6th months, and 1 year after the surgery. Patients with myopic regression were examined monthly until enhancement. The patients were assessed by complete ocular examinations. The main outcome measures were refraction (cycloplegic and manifest) and corneal topography. Patients with topographic signs suggesting corneal ectasia, under correction, corneal haze, or other complications were excluded from the study. The patients with myopic regression were only included in this study. Patients were encouraged to return after surgery for an examination if their vision declined. Enhancement surgery was offered when needed (patient dissatisfaction with the visual result). Enhancement was done by re-lifting the flap and treating the stromal bed for all patients with myopic regression (no dropout). The patients were operated on, examined, and followed-up by one surgeon (AAG).

\section{Data collection}

The medical records of the patients with refractive regressions were reviewed. The demographic and pre-operative data were collected (age, sex, pre-operative refraction, axial length, keratometric reading, and corneal topography). In this study, refractive myopic regression will be considered as a myopic shift of $\geq 0.5 \mathrm{D}$ in cycloplegic refraction after LASIK full correction.

The tenets of the Helsinki Declaration were followed in this study. It was reviewed and agreed by the Faculty of Medicine, Suez Canal University research ethics committee. Informed consent was not necessary for the analysis of the medical records due to the retrospective design of the study and the large sample size.

\section{Statistical analysis}

All data manipulation and analysis were performed by the Statistical Package for the Social Sciences (SPSS) version 25 (IBM Corporation, NY, USA). Parameters of the study groups were presented as frequencies and percentages or mean values and standard deviations. The student's $t$ test was used to compare the differences between means in the groups. Differences between frequencies in the groups were compared by the Chi-square test or Fisher's exact test (if $>$ $20 \%$ of expected values were less than 5). To compare the difference in the mean measurements between the subgroups of myopia, one-way ANOVA was performed. Shapiro-Wilk's test was used to test for data normality. Graphs were performed with GraphPad Prism (version 5.00 for Windows, GraphPad Software, La Jolla, CA, USA). A $p$ value $<0.05$ was considered statistically significant. 
Table 1 The characteristics of all patients (pre-operative)

\begin{tabular}{ll}
\hline The characteristics & All eyes \\
\hline Eyes: $n$ & 2316 \\
Sex: $n,(\%)$ & $1610(69.5 \%)$ \\
Female & $706(30.5 \%)$ \\
Male & \\
Age (yrs) & $26.4 \pm 6.8$ \\
Mean \pm SD & $(21$ to 50$)$ \\
Range & \\
SE (D) & $-4.3 \pm 2.1$ \\
Mean \pm SD & $(-0.5$ to -10.0$)$ \\
Range & \\
$K$ min (D) & $43.3 \pm 1.7$ \\
Mean \pm SD & $(38.5$ to 48.9$)$ \\
Range & \\
$K$ max(D) & $44.8 \pm 1.2$ \\
Mean \pm SD & $(39.9$ to 49.6$)$ \\
Range & \\
\hline
\end{tabular}

$n$ number, $S E$ spherical equivalent, $K \min$ minimum keratometric power, $K \max$ maximum keratometric power, yrs years, $D$ diopter, $S D$ standard deviation

\section{Results}

This study included 1219 patients (2316 eyes) with myopia. Mean \pm SD of pre-operative spherical equivalent (SE) was $4.3 \pm 2.1 \mathrm{D}$, range $(-0.50$ to $-10.00 \mathrm{D})$. Mean $\pm \mathrm{SD}$ age of the patients was $26.4 \pm 6.8$ years, range ( 21 to 50 years). Male to female ratio was 30.5 to $69.5 \%$. Mean $\pm \mathrm{SD}$ of the $\mathrm{K}$ min was $43.3 \pm 1.7 \mathrm{D}$, range ( 38.5 to $48.9 \mathrm{D}$ ), and of the $\mathrm{K}$ max was $44.8 \pm 1.2 \mathrm{D}$, range ( 39.9 to $49.6 \mathrm{D})$. The cumulative incidence rate of myopic regression according to the medical records of the patients was $25.12 \%$ (582 eyes out of total 2316 eyes) along the 2 years of this study ( $12.6 \%$ per year). The characteristics of all patients are presented in Table 1.

The total myopic eyes were classified according to the pre-operative refraction into three sub-groups: low myopia $>-3.0 \mathrm{D}$, moderate myopia -3.0 to $>-6.0 \mathrm{D}$, and high myopia $\leq-6.0 \mathrm{D}$. In total, $49.2 \%$ had pre-operative low myopia with mean $\pm \mathrm{SD}$ of $-2.3 \pm 0.7,35.84 \%$ had preoperative moderate myopia with mean \pm SD of $-4.9 \pm$ 1.2 , and $14.94 \%$ had pre-operative high myopia with mean $\pm \mathrm{SD}$ of $-8.4 \pm 1.8$. The characteristics of each group are presented in Table 2.

Eyes with post-LASIK myopic regression were classified according to their pre-operative refraction into three sub-groups:

- $13.4 \%$ had pre-operative low myopia with mean $\pm \mathrm{SD}-$ $2.75 \pm 0.1 \mathrm{D}$.

- $34 \%$ had pre-operative moderate myopia with mean $\pm \mathrm{SD}$ $-4.43 \pm 0.73 \mathrm{D}$.

- $52.6 \%$ of the patients had pre-operative high myopia with mean $\pm \mathrm{SD}-7.91 \pm 1.45 \mathrm{D}$.

The characteristics of those patients are presented in Table 3.
Table 2 The total myopic eyes classified according to the preoperative refraction into three sub-groups

\begin{tabular}{|c|c|c|c|c|}
\hline & \multicolumn{3}{|c|}{$\begin{array}{l}\text { Total myopic eyes }(n=2316) \\
n(\text { column } \%)\end{array}$} & \multirow[t]{2}{*}{$P$ value } \\
\hline & Low $>-3.0 \mathrm{D}$ & Moderate -3.0 to $>-6.0 \mathrm{D}$ & High $\leq-6.0 \mathrm{D}$ & \\
\hline Number $(\%)$ & $1140(49.2 \%)$ & $830(35.84 \%)$ & $346(14.94 \%)$ & \multirow{4}{*}{$\overline{0} .0111^{*}$} \\
\hline \multicolumn{4}{|l|}{ Age (yrs) } & \\
\hline Mean \pm SD & $26.4 \pm 6.2$ & $26.6 \pm 6.6$ & $27.6 \pm 7.4$ & \\
\hline Range & (21 to 50$)$ & (21 to 50$)$ & (21 to 50$)$ & \\
\hline \multicolumn{4}{|l|}{ Sex: $n,(\%)$} & \multirow[t]{3}{*}{$0.022 *$} \\
\hline Male & $480(42.1 \%)$ & $312(37.6 \%)$ & $158(45.7 \%)$ & \\
\hline Female & $660(57.9 \%)$ & $518(62.4 \%)$ & $188(54.3 \%)$ & \\
\hline \multicolumn{4}{|l|}{ Eye: $n(\%)$} & \multirow[t]{3}{*}{0.790} \\
\hline Right & $574(50.4 \%)$ & $408(49.15 \%)$ & $168(48.6 \%)$ & \\
\hline Left & $566(49.6 \%)$ & $422(50.85 \%)$ & $178(51.4 \%)$ & \\
\hline \multicolumn{4}{|l|}{ SE(D): } & \multirow[t]{3}{*}{$<0.001 *$} \\
\hline Mean \pm SD & $-2.3 \pm 0.7$ & $-4.9 \pm 1.2$ & $-8.4 \pm 1.8$ & \\
\hline Range & $(-0.5$ to -2.75$)$ & $(-3.0$ to -5.75$)$ & $(-6.0$ to -10.0$)$ & \\
\hline \multicolumn{4}{|l|}{$K \min (\mathrm{D})$} & \multirow[t]{3}{*}{$<0.001 *$} \\
\hline Mean \pm SD & $43.3 \pm 1.3$ & $43.7 \pm 1.4$ & $43.9 \pm 1.6$ & \\
\hline Range & (38.5 to 47.9$)$ & (38.7 to 47.8 ) & (40.0 to 48.1 ) & \\
\hline \multicolumn{4}{|l|}{$\mathrm{K} 2 \max (\mathrm{D})$} & \multirow[t]{3}{*}{$<0.001 *$} \\
\hline Mean \pm SD & $44.4 \pm 1.7$ & $44.7 \pm 1.4$ & $45.2 \pm 1.5$ & \\
\hline Range & (40.2 to 49.0$)$ & (41.4 to 49.6 ) & (42.1 to 49.6 ) & \\
\hline
\end{tabular}

$S E$ spherical equivalent, $n$ number, $y r s$ years, $S D$ standard deviation, $D$ diopter, $K$ min minimum keratometric power, $K \max$ maximum keratometric power

*Statistically significant 
Table 3 The characteristics of eyes with Post-LASIK myopic regression

Table 4 Characteristics of the eyes with post-LASIK stable refractions and the eyes with postLASIK myopic regression

\begin{tabular}{|c|c|c|c|c|}
\hline & \multicolumn{3}{|c|}{$\begin{array}{l}\text { Patients with myopic regression }(n=582) \\
n(\text { column } \%)\end{array}$} & \multirow[t]{2}{*}{$P$ value } \\
\hline & $\begin{array}{l}\text { Low myopia } \\
>-3.0 \mathrm{D}\end{array}$ & $\begin{array}{l}\text { Moderate myopia } \\
-3.0 \text { to }>-6.0 \mathrm{D}\end{array}$ & $\begin{array}{l}\text { High myopia } \\
\leq-6.0 \mathrm{D}\end{array}$ & \\
\hline Number (\%) & $78(13.4 \%)$ & $198(34 \%)$ & $306(52.6 \%)$ & --- \\
\hline \multicolumn{5}{|l|}{ Age (yrs) } \\
\hline Mean \pm SD & $21 \pm 0.1$ & $24.6 \pm 5.1$ & $25.65 \pm 6.8$ & 0.166 \\
\hline Range & (21 to 29 ) & (21 to 36$)$ & (21 to 39 ) & \\
\hline \multicolumn{5}{|l|}{ Sex: $n,(\%)$} \\
\hline Male & $28(36 \%)$ & $124(62.6 \%)$ & $108(35.3 \%)$ & $<0.001 *$ \\
\hline Female & $50(64 \%)$ & $74(37.4 \%)$ & $198(64.7 \%)$ & \\
\hline \multicolumn{5}{|l|}{ Eye: $n,(\%)$} \\
\hline Right & $40(51 \%)$ & $74(37.4 \%)$ & $200(65.4 \%)$ & $<0.001 *$ \\
\hline Left & $38(49 \%)$ & $124(62.6 \%)$ & $106(34.6 \%)$ & \\
\hline \multicolumn{5}{|l|}{$\mathrm{SE}(\mathrm{D}):$} \\
\hline Mean \pm SD & $-2.75 \pm 0.1$ & $-4.43 \pm 0.73$ & $-7.91 \pm 1.45$ & $<0.001^{*}$ \\
\hline Range & $(-2.50$ to -2.75$)$ & $(-3.50$ to -5.5$)$ & $(-6.25$ to -10.0$)$ & \\
\hline \multicolumn{5}{|l|}{$\mathrm{K} \min (\mathrm{D})$} \\
\hline Mean \pm SD & $40.07 \pm 0.12$ & $41.49 \pm 1.42$ & $43.52 \pm 1.35$ & $0.001 *$ \\
\hline Range & (39.97 to 40.2 ) & (39.82 to 44.01 ) & (41.6 to 45.23 ) & \\
\hline \multicolumn{5}{|l|}{$\mathrm{K} \max (\mathrm{D})$} \\
\hline Mean \pm SD & $42.06 \pm 0.08$ & $43.34 \pm 1.35$ & $44.96 \pm 1.24$ & $0.001 *$ \\
\hline Range & (41.99 to 42.13 ) & (41.7 to 45.7 ) & (42.4 to 46.7 ) & \\
\hline
\end{tabular}

$S E$ spherical equivalent, $n$ number, $y r s$ years, $S D$ standard deviation, $D$ diopter, $K$ min minimum keratometric power, $K \max$ maximum keratometric power

*Statistically significant

\begin{tabular}{|c|c|c|c|}
\hline & \multicolumn{2}{|l|}{$\begin{array}{l}\text { Total eyes }(n=2316) \\
n(\text { column } \%)\end{array}$} & \multirow[t]{2}{*}{$P$ value } \\
\hline & $\begin{array}{l}\text { Eyes with stable } \\
\text { refraction }(n=1734)\end{array}$ & $\begin{array}{l}\text { Eyes with myopic } \\
\text { regression }(n=582)\end{array}$ & \\
\hline Axial length & & & $<0.001^{*}$ \\
\hline Mean $\pm \mathrm{SD}$ & $24.38 \pm 0.73$ & $26.6 \pm 0.44$ & \\
\hline Range & 22.9 to 25.9 & 26.0 to 27.86 & \\
\hline Age (yrs) & & & 0.847 \\
\hline Mean \pm SD & $25.0 \pm 5.7$ & $24.8 \pm 6.0$ & \\
\hline Range & (21 to 50 ) & (21 to 39$)$ & \\
\hline Sex: $n,(\%)$ & & & $<0.001 *$ \\
\hline Male & $290(16.7 \%)$ & $218(37.5 \%)$ & \\
\hline Female & $1444(83.3 \%)$ & $364(62.5 \%)$ & \\
\hline Eye: $n,(\%)$ & & & $0.0004 *$ \\
\hline Right & $830(47.9 \%)$ & $328(56.4 \%)$ & \\
\hline Left & $904(52.1 \%)$ & $254(43.6 \%)$ & \\
\hline SE(D) & & & $<0.001 *$ \\
\hline Mean $\pm \mathrm{SD}$ & $-3.3 \pm 1.7$ & $-7.5 \pm 2.3$ & \\
\hline Range & $(-0.5$ to -10.0$)$ & $(-4.5$ to -10.0$)$ & \\
\hline$K \min (\mathrm{D}):$ & & & $0.001 *$ \\
\hline Mean \pm SD & $43.7 \pm 1.5$ & $42.6 \pm 1.8$ & \\
\hline Range & (40.4 to 49.0 ) & (39.8 to 45.2$)$ & \\
\hline$K \max (\mathrm{D})$ & & & 0.0685 \\
\hline Mean \pm SD & $44.8 \pm 1.6$ & $44.2 \pm 1.6$ & \\
\hline Range & (41.7 to 49.6 ) & (41.3 to 46.7 ) & \\
\hline
\end{tabular}

$S E$ spherical equivalent, $n$ number, $y r s$ years, $S D$ standard deviation, $D$ diopter, $K$ min minimum keratometric power, $K \max$ maximum keratometric power

*Statistically significant 
Fig. 1 Mean of the axial length in eyes with stable refraction and eyes with myopic regression. There is a statistically significant difference between the two groups $(P<0.001)$

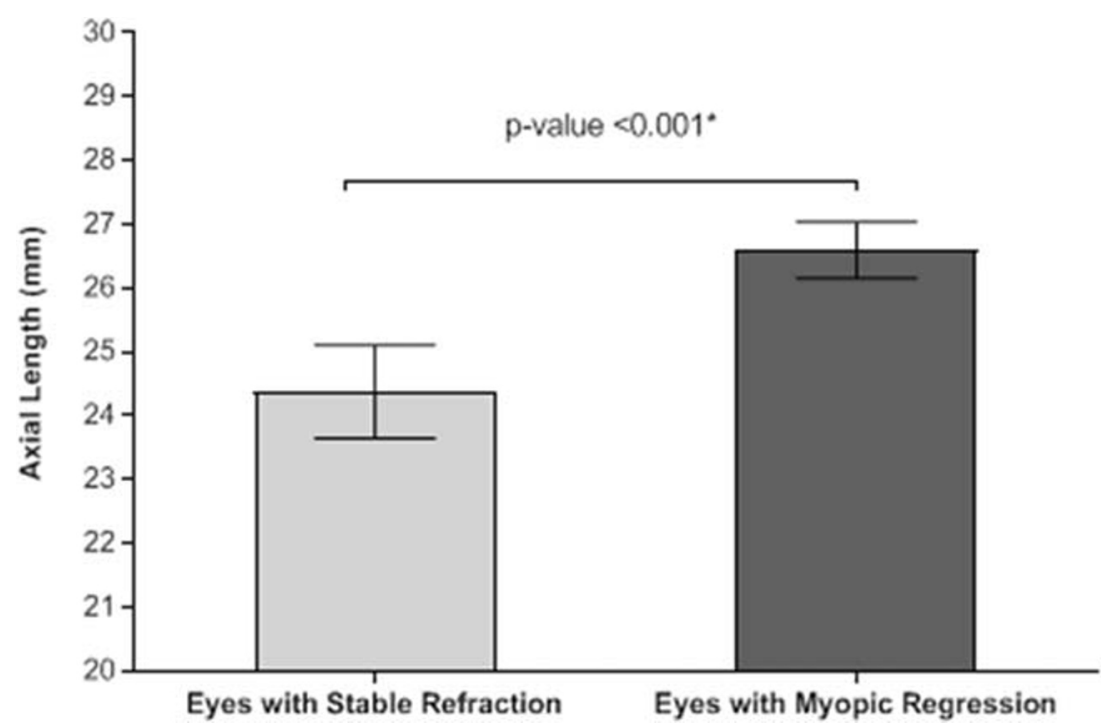

The mean \pm SD of the axial length of the patients with myopic regression was $26.6 \pm 0.44 \mathrm{~mm}$, range (26.0 to $27.86 \mathrm{~mm}$ ), while the mean $\pm \mathrm{SD}$ of the axial length of other patients with stable refraction was $24.38 \pm 0.73 \mathrm{~mm}$, range $(22.9$ to $25.9 \mathrm{~mm})$ ( $t$ test statistic $=69.3 ; P$ value $<0.001)$. The characteristics of the eyes with post-LASIK stable refractions and the eyes with myopic regression are presented in Table 4 and Fig. 1. The mean \pm SD of the time between initial correction and regression was $3.0 \pm 1.0$ months; Fig. 2 shows the survival curve of the total eyes. About $3 \%$ of all studied eyes developed myopic regression at the 1st month, compared to $5.8 \%, 1.6 \%, 0.9 \%$, and $0.1 \%$ at $3 \mathrm{rd}, 4$ th, 5 th, and 6 th month, respectively. Figure 3 shows the survival curve of postLASIK myopic regression according to the pre-operative myopic sub-groups. There were significantly unequal survival distributions for the different levels of pre-operative myopic sub-groups (Log Rank test $=590.3 ; P$ value $<0.001)$.
Compared to eyes with pre-operative low myopia, eyes with pre-operative high and moderate myopia had significantly less mean survival time (9.99 and 3.99, versus 11.38 months). Further, eyes with pre-operative high myopia developed myopic regression at earlier months of the follow-up period, compared to eyes with moderate and low myopia (1st versus 3 rd month).

The higher degrees of myopia were predictors of the need for retreatment. In total, $88.4 \%$ of the patients with preoperative high myopia and axial length $\geq 26 \mathrm{~mm}$ had myopic regression, $23.8 \%$ of the patients with pre-operative moderate myopia and axial length $\geq 26 \mathrm{~mm}$ have myopic regression and $6.8 \%$ of the patients with pre-operative low myopia, and axial length $\geq 26 \mathrm{~mm}$ have myopic regression (Table 5 and Fig. 4). Figure 5 describes the scatter plot of axial length versus myopic regression. It shows that the amount of myopic regression was significantly and positively correlated with the pre-
Fig. 2 Survival curve of the total eyes shows that all myopic regression occurred during the first 6 post-operative months, with a mean survival time among eyes with myopic regression of $3.0 \pm 1.0$ months

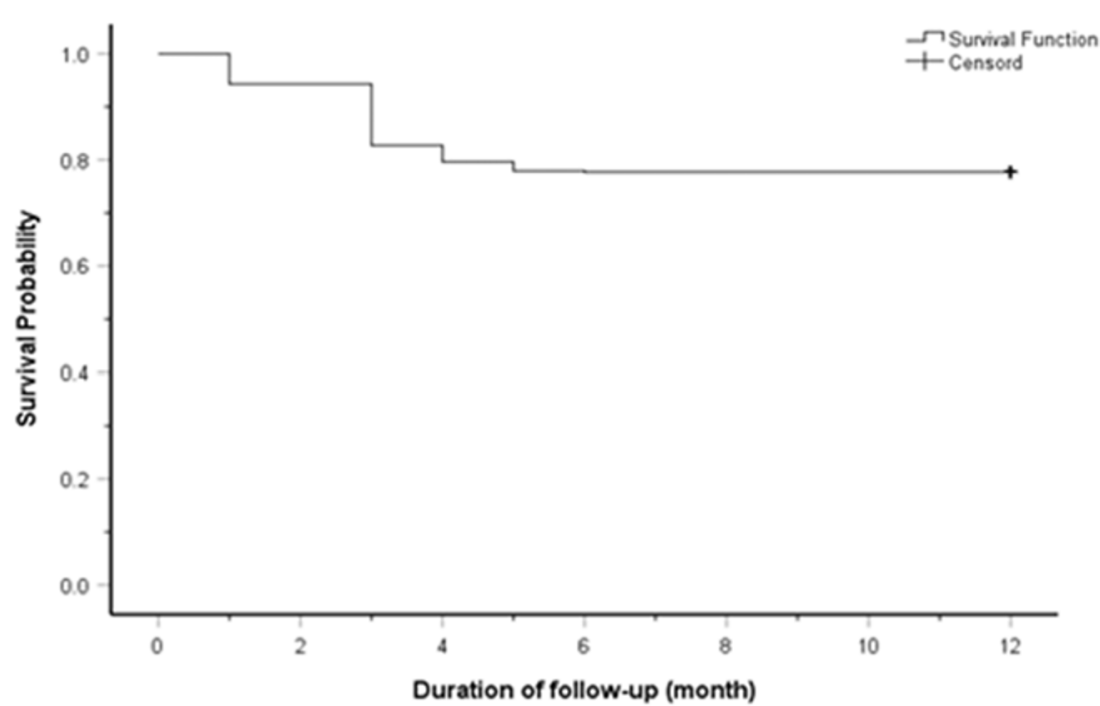


Fig. 3 Survival curve of postLASIK myopic regression according to the pre-operative myopic sub-groups

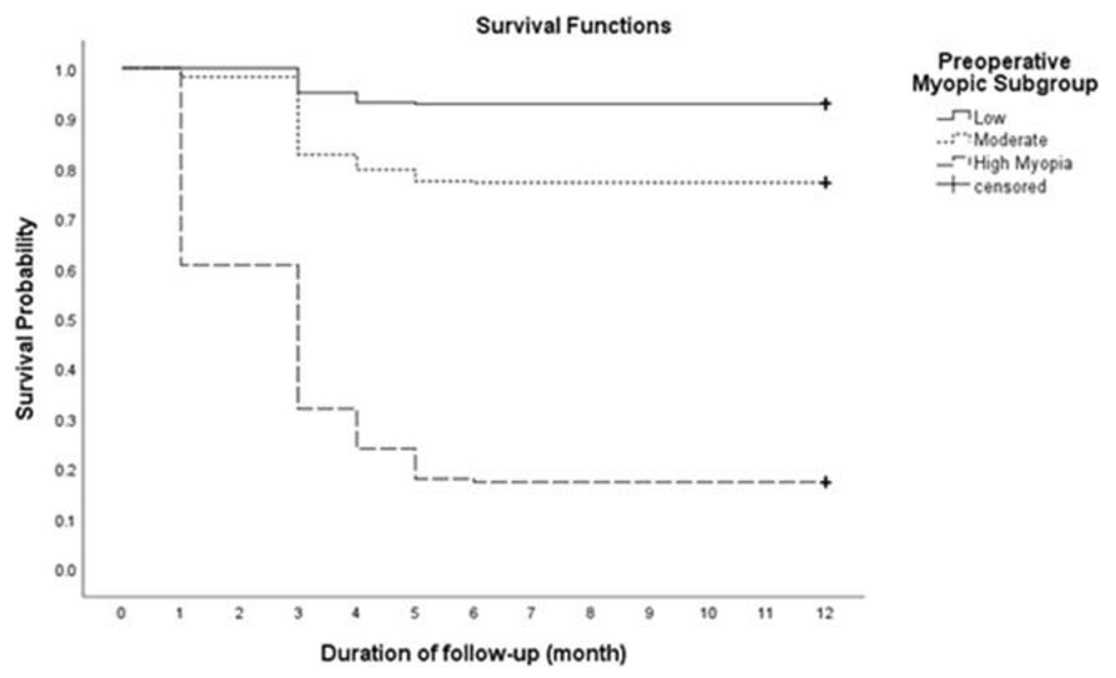

operative axial length (Pearson's correlation coefficient $=$ 0.597; $P$ value $<0.001)$.

In the classification of the eyes with post-LASIK myopic regression regarding the degree of regression, in 77 eyes $(13.2 \%)$, the myopic regression was $<1.0 \mathrm{D}$, in 246 eyes $(42.2 \%)$, the regression was 1.0 to $2.0 \mathrm{D}$, and in 260 eyes (44.6\%), the regression was $>2.0 \mathrm{D}$ (Fig. 6).

The differences between mean $K$ values at the $1 \mathrm{st}$ month, 6th month, and 12 th month post-operative in both eyes with stable refraction and eyes with myopic regression were non-significant $(\mathrm{P} 1=0.154$ and $\mathrm{P} 2=0.970$, respectively) (Table 6). The differences between the preoperative axial length and along the 12-month follow-up time of both eyes with stable refraction and eyes with myopic regression are presented in Table 7 . There was a statistically significant increase in the axial length $\left(p<0.001^{*}\right)$ along follow-up time in eyes with myopic regression compared to eyes with stable refraction $(P=$

Table 5 Percentage of patients with myopic regression and axial length $\geq 26 \mathrm{~mm}$

\begin{tabular}{llllll}
\hline & & \multicolumn{2}{l}{ Myopia $n($ column $\%)$} & \multirow{2}{*}{ Total eyes } & \\
\cline { 3 - 6 } & & Low $>-3.0 \mathrm{D}$ & Moderate -3.0 to $>-6.0 \mathrm{D}$ & High $\leq-6.0 \mathrm{D}$ & \\
\hline \multirow{2}{*}{ Axial length } & $<26 \mathrm{~mm}$ & $1062(93.2 \%)$ & $632(76.2 \%)$ & $40(11.6 \%)$ & 1734 \\
& $\geq 26 \mathrm{~mm}$ & $78(6.8 \%)$ & $198(23.8 \%)$ & $306(88.4 \%)$ & 582 \\
& Total eyes & 1140 & 830 & 346 & 2316 \\
\hline
\end{tabular}

$n$ number

*Statistically significant

Fig. 4 Percentage of patients with myopic regression and axial length $\geq 26 \mathrm{~mm}$

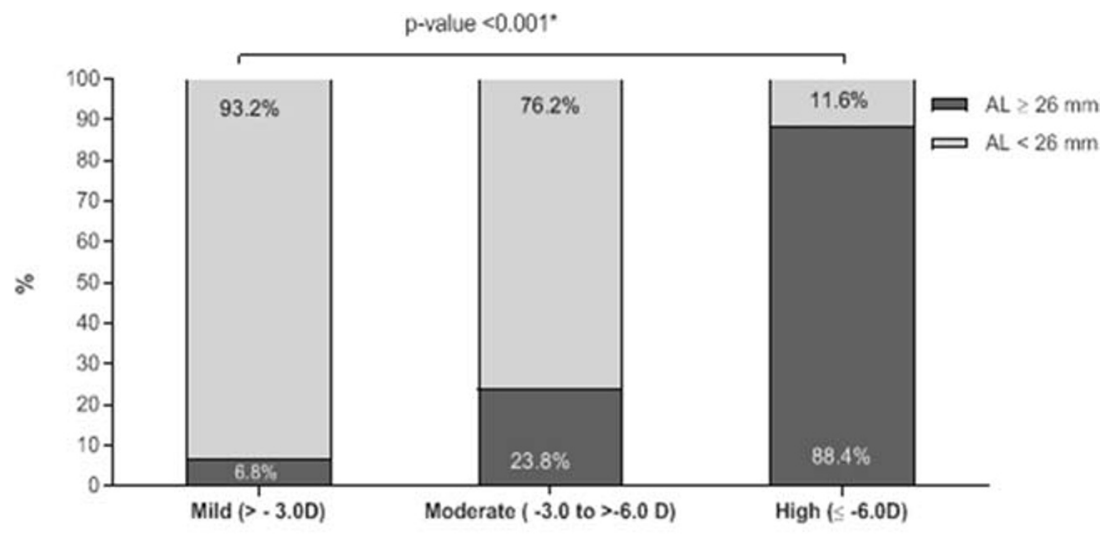

Myopia Sub-groups 
Fig. 5 Scatter plot of axial length versus myopic regression

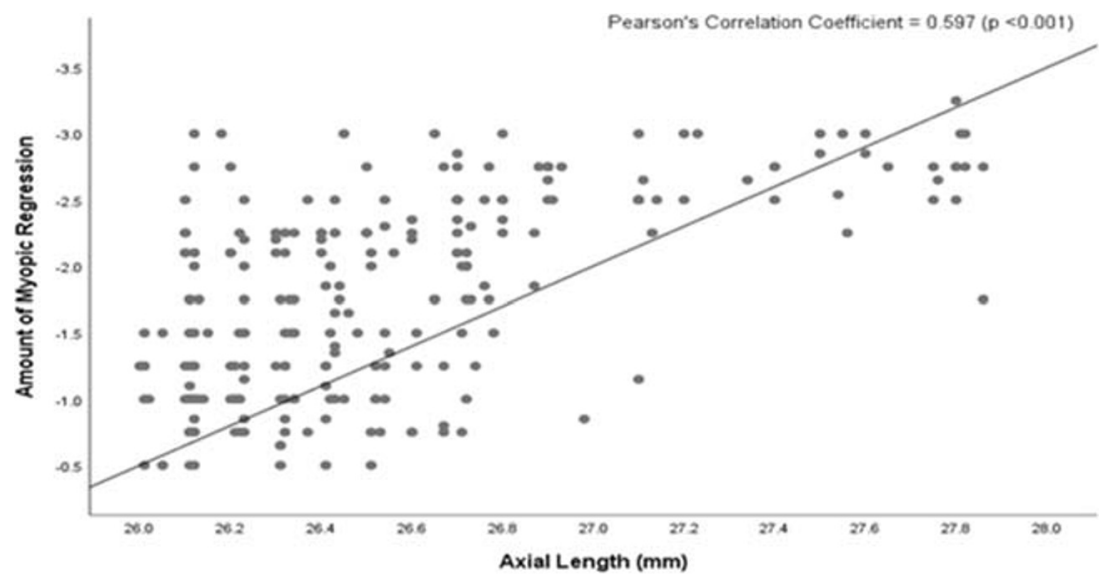

0.580). Mean $\pm \mathrm{SD}$ of spherical equivalent (SE) along the 12-month follow-up time of both eyes with stable refraction and after LASIK enhancement in eyes with myopic regression are presented in Table 8. At the end of the follow-up time, eyes with stable refraction had a mean \pm $\mathrm{SD}$ of $+0.21 \pm 0.1 \mathrm{D}$, and eyes with myopic regressions had a mean $\pm \mathrm{SD}$ of $-0.99 \pm 0.39 \mathrm{D}$. Figure 7 shows the spherical equivalent (SE) pre-operatively and at 1st-day, 1st-week, 1st-month, 3rd-month, 6th-month, and the 12thmonth follow-up time after LASIK in the three myopic sub-groups with stable refraction. Spherical equivalent
(SE) reduction was statistically significant from the $1 \mathrm{st}$ day post-LASIK $(P<0.001 *)$, with no myopic regression during the remaining follow-up time.

\section{Discussion}

High pre-operative sphere, high astigmatism, corneal steepness, and older age have been well recognized to be associated with retreatment significantly [10-12]. Post-LASIK compensatory epithelial hyperplasia $(\mathrm{CEH})$ is still a debate between researchers,
Fig. 6 Percentage of post-LASIK myopic regression according to the degree of progression in diopter

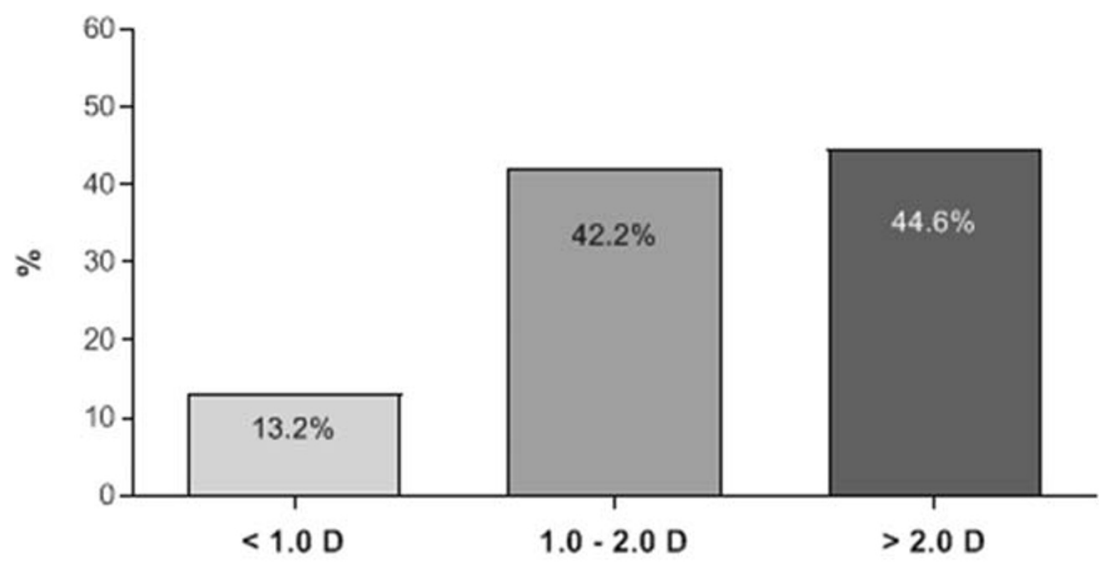

Degree of Myopic Regression

Table 6 Mean of $K$ reading early post-operative and at the 12-month follow-up time of both eyes with stable refraction and eyes with myopic regression

\begin{tabular}{|c|c|c|c|c|c|c|c|c|}
\hline & \multicolumn{3}{|c|}{ Eyes with stable refraction } & \multirow[t]{2}{*}{ P1-value } & \multicolumn{3}{|c|}{ Eyes with myopic regression } & \multirow[t]{2}{*}{ P2-value } \\
\hline & 1 st month & 6th month & 12th month & & 1st month & 6th month & 12th month & \\
\hline $\begin{array}{l}\text { Mean K (D) } \\
\text { Mean } \pm \text { SD } \\
\text { (range) }\end{array}$ & $\begin{array}{l}37.6 \pm 1.8 \\
(34.3 \text { to } 42.4)\end{array}$ & $\begin{array}{l}37.6 \pm 1.75 \\
(34.2 \text { to } 42.36)\end{array}$ & $\begin{array}{l}37.5 \pm 1.73 \\
(34.23 \text { to } 42.35)\end{array}$ & 0.153 & $\begin{array}{l}38.1 \pm 1.63 \\
(35.2 \text { to } 41.4)\end{array}$ & $\begin{array}{l}38.12 \pm 1.59 \\
(35.4 \text { to } 41.38)\end{array}$ & $\begin{array}{l}38.12 \pm 1.58 \\
(35.36 \text { to } 41.37)\end{array}$ & 0.970 \\
\hline
\end{tabular}



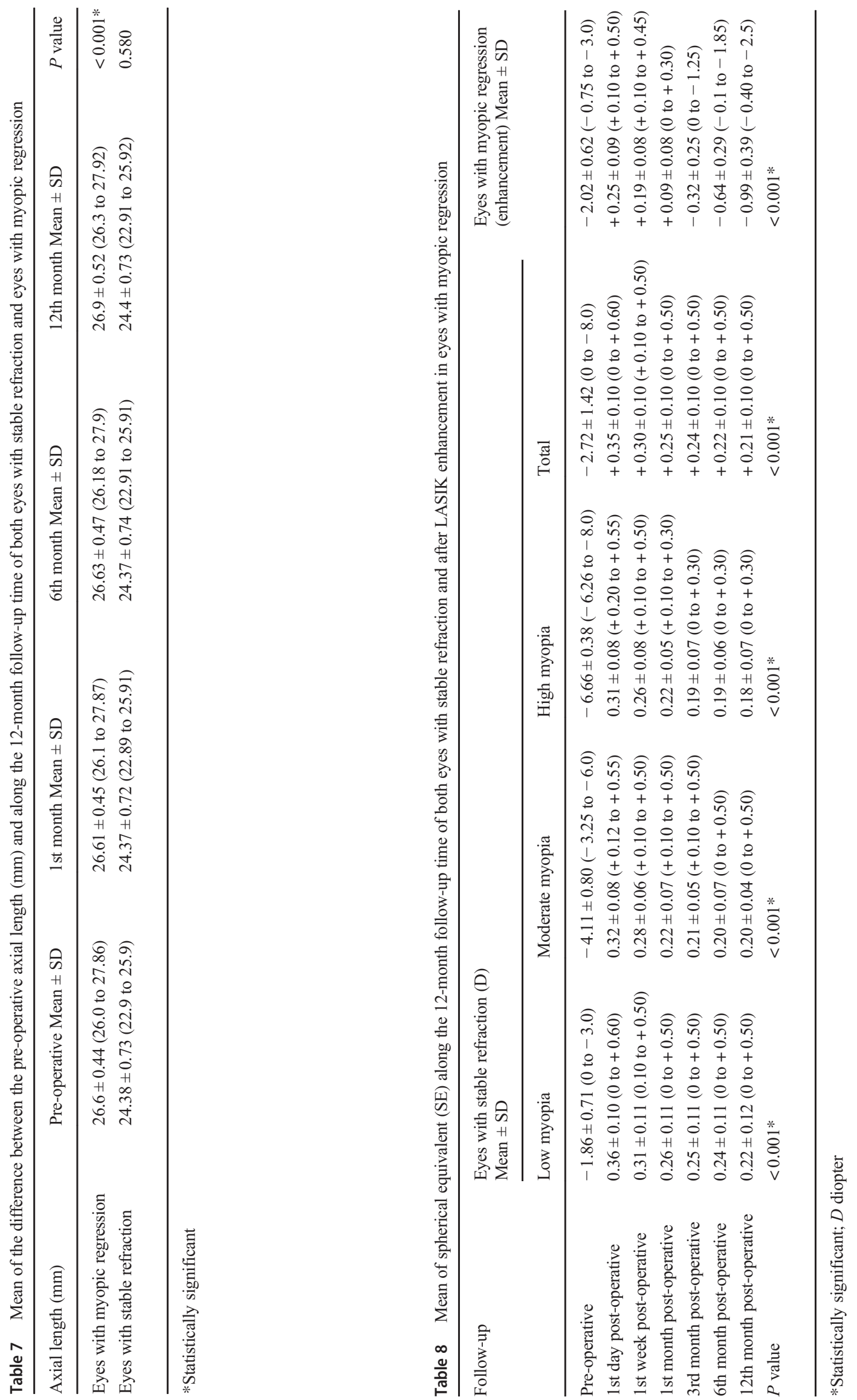
Fig. 7 Refractive stability of mean \pm SD refractive spherical equivalent between pre-operative and post-operative follow-up time in the 3 myopic sub-groups with stable refraction

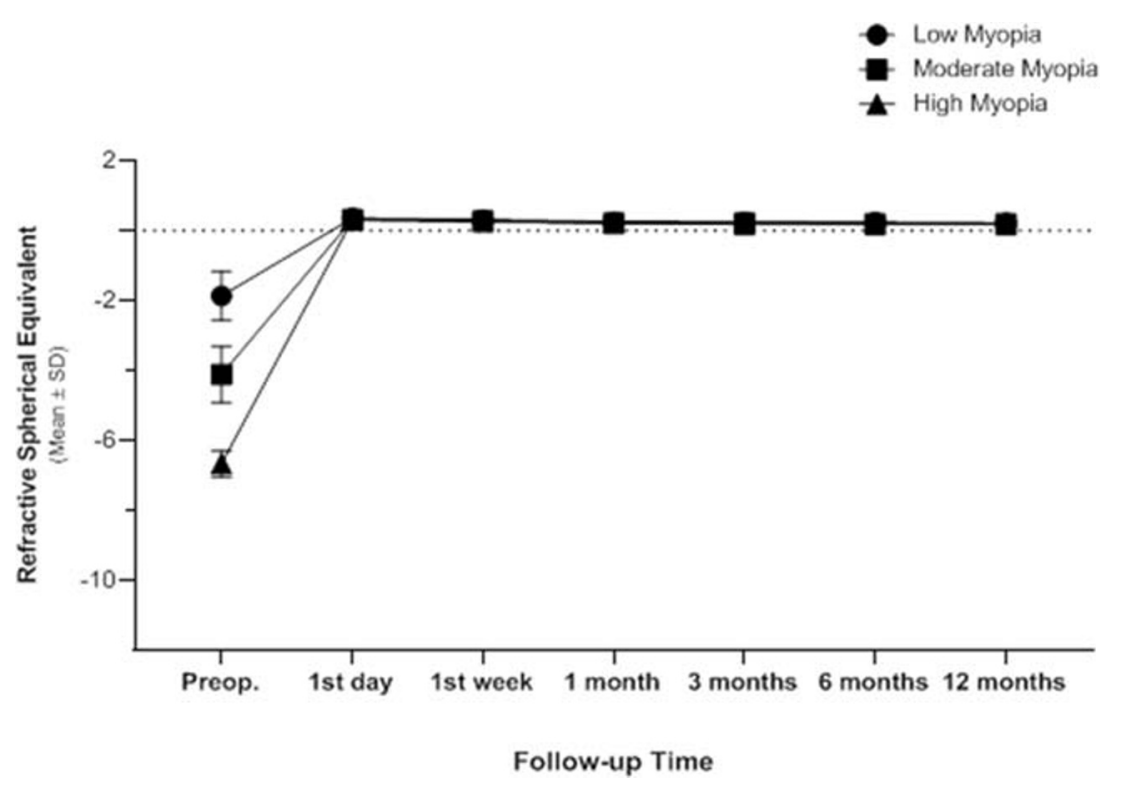

and some report post-LASIK increase in CEH and causes of myopic regression [13-15]; however, others [12, 16] did not report any correlation between $\mathrm{CEH}$ and regression.

As far as it is known, this retrospective study is the first to analyse the relationship between the refractive regression and the axial length in myopic patients. It reports that pre-operative high axial length $\geq 26 \mathrm{~mm}$ increases the risk of having myopic regression after LASIK. In this study, $25.13 \%$ of the patients have an axial length $\geq 26 \mathrm{~mm}$, and all these patients have a myopic regression with varying degrees according to the pre-operative primary treatment. The term myopic regression suggests the loss of effect from the LASIK ablation delivered to match a certain level of myopic refraction at the initial treatment. It suggests a reduction as opposed to the term "progression" which better defines what has happened to these patients. The term LASIK regression would suggest reduction in effect from the laser ablative procedure and not progressive myopia or increase in axial length as deduced by this paper.

Some researchers [17] stated that by the age of 13 years, the axial length of the eye reaches the adult length. So, the eye could not elongate later on. On the other hand, Gudmundsdottir and associates [18] supported that the axial length of the eye changes in adults. They recorded that the mean axial length $23.6 \pm 1.1 \mathrm{~mm}$ decreased to $23.2 \pm 1.4 \mathrm{~mm}$ along with the 9 years of the study in 50-year-old participants. Fotedar and associates [19] recorded that with age, axial length decreased from a mean of 23.6 to $23.2 \mathrm{~mm}$ in the patients aged 85 years along with the 10 -year study.

On the other hand, McBrien and Adams [20] investigated the biometric and refractive changes with myopia in adults (average of $-3.74 \mathrm{D})$. They recorded that $48 \%$ of the study sample had an increase in the myopia of $0.37 \mathrm{D}$ or more during the 2-year time of the study, and this result was because of the elongation of the vitreous body. Fledelius and Goldschmidt [21] recorded a statistically significant increase in the mean of the axial length from $26.7 \pm 1.3 \mathrm{~mm}$ at 26 years old to $27.5 \pm 2.1 \mathrm{~mm}$ at 54 years old. Some researchers $[22,23]$ also proposed that, when myopia increases with age, we have to think about the potential increase of axial length in adding to suspect the development of nuclear cataract. These show that in adults, increased myopia with age is because of an increased depth of the vitreous cavity which causes an elongation of the axial length of the eye regardless of the degree of myopia.

Present results strongly suggest that patients with high axial length ( $\geq 26 \mathrm{~mm}$ ) might be increasingly vulnerable to mechanical factors, for example, changing in IOP that can cause stretching of the sclera and increasing the length of the vitreous cavity because of a thin sclera which is considered causing the refractive regression. Also, the relationship between axial length and corneal biomechanics changes after the LASIK was not fully understood and needs further investigations. Wong YZ and Lam AK [24] concluded that patients with high axial length exhibited lower corneal hysteresis than emmetropes. BuenoGimeno et al. [25] also recorded that lower levels of corneal hysteresis were associated with longer axial length, and corneal biomechanical properties appeared to be compromised in myopia from an early age, mainly in high myopia. However, some eyes without a posterior staphyloma at the time of the primary treatment may develop it later on overtime.

The present study has some limitations: it is a retrospective study; only successive patients who completed the follow-up period were included (considering the patients who did not complete the follow-up regimen as satisfied patients with their post-LASIK refractive outcome).

In summary, our results support that pre-operative high axial length significantly increases the risk of having myopic regression after LASIK. It should be one of the pre-operative assessment measures for LASIK patients because it could give 
us an essential clue of post-operative stability and efficacy, not only in high myopic patients but also in low myopic patients as some of them have long axial length. These patients should be closely monitored and followed up regularly.

\section{Compliance with ethical standards}

Conflict of interest The author declares that he has no conflicts of interest.

Ethical approval The tenets of the Helsinki Declaration were followed in this study. It was reviewed and agreed by the Faculty of Medicine, Suez Canal University research ethics committee.

Informed consent Informed consent was not necessary for the analysis of the medical records due to the retrospective design of the study and the large sample size.

Open Access This article is licensed under a Creative Commons Attribution 4.0 International License, which permits use, sharing, adaptation, distribution and reproduction in any medium or format, as long as you give appropriate credit to the original author(s) and the source, provide a link to the Creative Commons licence, and indicate if changes were made. The images or other third party material in this article are included in the article's Creative Commons licence, unless indicated otherwise in a credit line to the material. If material is not included in the article's Creative Commons licence and your intended use is not permitted by statutory regulation or exceeds the permitted use, you will need to obtain permission directly from the copyright holder. To view a copy of this licence, visit http://creativecommons.org/licenses/by/4.0/.

\section{References}

1. Yan MK, Chang JS, Chan TC (2018) Refractive regression after laser in situ keratomileusis. Clin Exp Ophthalmol 46(8):934-944

2. Lim SA, Park Y, Cheong YJ, Na KS, Joo CK (2016) Factors affecting long-term myopic regression after laser in situ keratomileusis and laser-assisted subepithelial keratectomy for moderate myopia. Korean J Ophthalmol 30(2):92-100

3. Miyata K, Tokunaga T, Nakahara M, Ohtani S, Nejima R, Kiuchi T, Kaji Y, Oshika T (2004) Residual bed thickness and corneal forward shift after laser in situ keratomileusis. J Cataract Refact Surg 30(5):1067-1072

4. Lin MY, Chang DC, Hsu WM, Wang IJ (2012) Cox proportional hazards model of myopic regression for laser in situ keratomileusis flap creation with a femtosecond laser and with a mechanical microkeratome. J Cataract Refract Surg 38(6):992-999

5. Ambrósio R Jr (2019) Post-LASIK ectasia: twenty years of a conundrum. Semin Ophthalmol 34(2):66-68

6. Patel NP, Clinch TE, Weis JR, Ahn C, Lundergan MK, Heidenreich K (2000) Comparison of visual results in initial and retreatment laser in situ keratomileusis procedures for myopia and astigmatism. Am J Ophthalmol 130(1):1-11

7. Hersh PS, Fry KL, Bishop DS (2003) Incidence and associations of retreatment after LASIK. Ophthalmology 110(4):748-754

8. Liu M, Gao H, Shi W (2019) Factors affecting myopic regression after laser in situ keratomileusis and laser-assisted subepithelial keratectomy for high myopia. Semin Ophthalmol 34(5):359-364

9. Randleman JB, White AJ Jr, Lynn MJ, Hu MH, Stulting RD (2009) Incidence, outcomes, and risk factors for retreatment after wavefront-optimized ablations with PRK and LASIK. J Refract Surg 25(3):273-276

10. Alio JL, Muftuoglu O, Ortiz D, Pérez-Santonja JJ, Artola A, Ayala MJ, Garcia MJ, de Luna GC (2008) Ten-year follow-up of laser in situ keratomileusis for myopia of up to -10 diopters. Am J Ophthalmol 145(1):46-54

11. Pokroy R, Mimouni M, Sela T, Munzer G, Kaiserman I (2016) Myopic laser in situ keratomileusis retreatment: incidence and associations. J Cataract Refract Surg 42(10):1408-1414

12. Zhou J, Gu W, Li S, Wu L, Gao Y, Guo X (2020) Predictors affecting myopic regression in $-6.0 \mathrm{D}$ to $-10.0 \mathrm{D}$ myopia after laser-assisted subepithelial keratomileusis and laser in situ keratomileusis flap creation with femtosecond laser-assisted or mechanical microkeratome-assisted. Int Ophthalmol 40(1):213-225

13. Reinstein DZ, Ameline B, Puech M, Montefiore G, Laroche L (2005) VHF digital ultrasound three-dimensional scanning in the diagnosis of myopic regression after corneal refractive surgery. J Refract Surg 21(5):480-484

14. Shen Y, Chen Z, Knorz MC, Li M, Zhao J, Zhou X (2014) Comparison of corneal deformation parameters after SMILE, LASEK, and femtosecond laser-assisted LASIK. J Refract Surg 30(5):310-318

15. Zhu W, Han Y, Cui C, Xu W, Wang X, Dou X, Xu L, Xu Y, Mu G (2018) Corneal collagen crosslinking combined with phototherapeutic keratectomy and photorefractive keratectomy for corneal ectasia after laser in situ keratomileusis. Ophthalmic Res 59(3):135-141

16. Sella S, Duvdevan-Strier N, Kaiserman I (2019) Unilateral refractive surgery and myopic progression. J Pediatr Ophthalmol Strabismus 56(2):78-82

17. Saka N, Ohno-Matsui K, Shimada N, Sueyoshi S, Nagaoka N, Hayashi W, Hayashi K, Moriyama M, Kojima A, Yasuzumi K, Yoshida T, Tokoro T, Mochizuki M (2010) Long term changes in axial length adult eyes with pathologic myopia. Am J Ophthalmol 150(4):562-568

18. Gudmundsdottir E, Arnarsson A, Jonasson F (2005) Five-year refractive changes in an adult population: Reykjavik Eye Study. Ophthalmology 112(4):672-677

19. Fotedar R, Mitchell P, Burlutsky G, Wang JJ (2008) Relationship of 10year change in refraction to nuclear cataract and axial length findings from an older population. Ophthalmology 115(8):1273-1278 1278e1

20. McBrien NA, Adams DW (1997) A longitudinal investigation of adult-onset and adult-progression of myopia in an occupational group. Refractive and biometric findings. Invest Ophthalmol Vis Sci 38(2):321-333

21. Fledelius HC, Goldschmidt E (2010) Oculometry findings in high myopia at adult age: considerations based on oculometric follow-up data over 28 years in a cohort-based Danish high-myopia series. Acta Ophthalmol 88(4):472-478

22. Pan CW, Boey PY, Cheng CY, Saw SM, Tay WT, Wang JJ, Tan AG, Mitchell P, Wong TY (2013) Myopia, axial length, and agerelated cataract: the Singapore Malay eye study. Invest Ophthalmol Vis Sci 54(7):4498-4502

23. Chong EW, Mehta JS (2016) High myopia and cataract surgery. Curr Opin Ophthalmol 27(1):45-50

24. Wong YZ, Lam AK (2015) The roles of cornea and axial length in corneal hysteresis among emmetropes and high myopes: a pilot study. Curr Eye Res 40(3):282-289

25. Bueno-Gimeno I, España-Gregori E, Gene-Sampedro A, Lanzagorta-Aresti A, Piñero-Llorens DP (2014) Relationship among corneal biomechanics, refractive error, and axial length. Optom Vis Sci 91(5):507-513

Publisher's note Springer Nature remains neutral with regard to jurisdictional claims in published maps and institutional affiliations. 